\title{
Multiple clustered dermatofibroma associated with asymptomatic pericardial cyst
}

\author{
Piotr Brzezinski $^{1}$, Viktoryia Kazlouskaya ${ }^{2}$, Cesar Bimbi ${ }^{3 *}$ \\ ${ }^{1}$ 6th Military Support Unit, Ustka, Department of Dermatology, os. Ledowo 1N, Ustka, Poland \\ ${ }^{2}$ SUNY Downstate, Department of Dermatology, Brooklyn, New York, USA \\ ${ }^{3}$ Institute of Dermatology Centro Historico, Dermatology, Porto Alegre, Brazil
}

\begin{abstract}
Multiple clustered dermatofibroma (MCDF) is an unusual variant of dermatofibroma (DF) presentation, localized on one segment of the body. Multiple dermatofibroma is a term for when there are more than 15 dermatofibromas, which in itself is already a rare condition. The dermatofibromas usually appear in younger adults and are predominantly located on lower parts of the body. No associations, except one case with pulmonary hypertension, were described in patients with MCDF. Herein we present another case of this rare complaint in a 58 year old female with clustered lesions on the thigh. Pericardial cyst was identified in our patient during routine chest X-ray and the patient is asymptomatic. MCDFs do not usually require treatment unless requested by the patient for cosmetic reason. This variant of MCDF, which is neither congenital nor eruptive, is extraordinarily rare, with only 13 cases reported. Further reports may identify possible associations of MCDF.
\end{abstract}

Keywords: dermatofibroma; histiocytomas; pericardial cyst

Citation: Brzezinski P, Kazlouskaya V, Bimbi C. Multiple clustered dermatofibroma associated with asymptomatic pericardial cyst. J Surg Dermatol 2021; 6(2): 156; http://dx.doi/10.18282/jsd.v6.i2.156.

*Correspondence to: Cesar Bimbi, Institute of Dermatology Centro Historico, Dermatology, Porto Alegre, Brazil; cbimbi@ terra.com.br

Received: $7^{\text {th }}$ April 2021; Accepted: $4^{\text {th }}$ May 2021; Published Online: $22^{\text {nd }}$ May 2021

\section{Introduction}

Dermatofibroma (DF) is a common benign fibrohistiocytic proliferation. While it is frequently seen in the routine practice of a dermatologist, it is sometimes difficult to establish a diagnosis without a skin biopsy, due to its multiple clinical and histopathological variations. Unusual clinical forms of DF include giant, atrophic, DF with satellite, polypoid, and subcutaneous. Multiple DFs are rare, eruptive and congenital forms are described. When DFs are grouped in one body segment, terms multiple clustered dermatofibroma (MCDF) or agminated DF are used. It is a rare condition and it is usually not associated with any systemic abnormalities. Correct diagnosis may prevent unnecessary tests and treatments.

\section{Case report}

A 58 year-old, otherwise healthy woman, was referred with a history of slightly pruritic reddish-brown papules and nodules grouped on the left buttock. She recalled that the first lesion appeared when she was 15 years old, with new lesions gradually appearing near the others. No history of trauma or insect bites was reported, with the lesions ceasing to grow by the fourth decade.

Physical examination showed dark brown firm lesions, 4 to $10-\mathrm{mm}$ in diameter, concentrated on the left buttock (Figures 1 and 2). There was no regional lymphadenopathy. Attempts to squeeze the lesions with the fingers lead to retraction beneath skin and a dimple forms (dimple sign), indicating tethering of the skin to the underlying fibrous tissue.

Two skin biopsies were taken and revealed poorly circumscribed spindle cell proliferation with underlying epidermal hyperplasia and rete ridges pigmentation (Figure $3)$. Thickened bundles of collagen were present at the periphery of the lesions (Figure 4). Based on clinical and histopathological presentation, the diagnosis of MCDF was established. The patient reported that she had a routine chest X-ray done several months ago and a possible cardiac mass was identified. Computer tomography was performed and was consistent with pericardial cyst $2.2 \times 3.48 \mathrm{~cm}$ in size. Patient is asymptomatic and continues to follow up with a cardiologist for the annual examination.

Copyright $@ 2021$ Brzezinski P, et. al. This is an Open Access article distributed under the terms of the Creative Commons Attribution-NonCommercial 4.0 International License (http://creativecommons.org/licenses/by-nc/4.0/), permitting all non-commercial use, distribution, and reproduction in any medium, provided the original work is properly cited. 


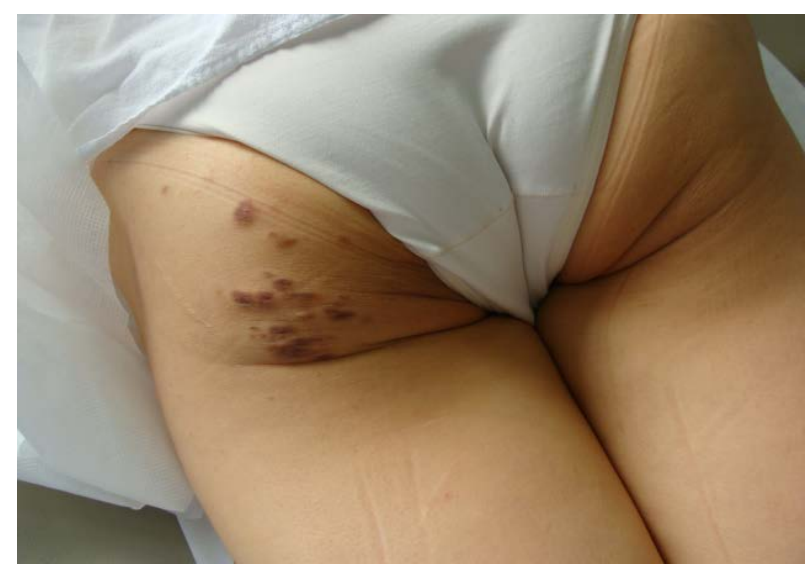

Figure 1. Multiple clustered lesions on the left thigh

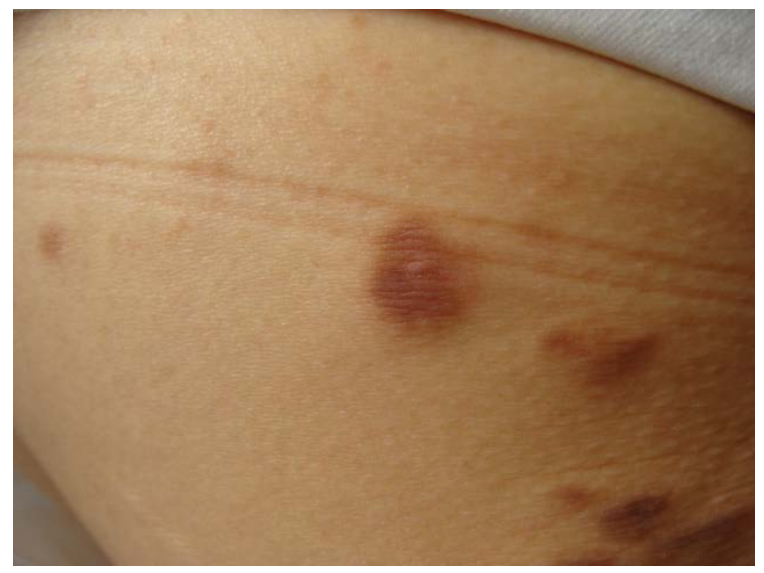

Figure 2. Closer look at the pigmented lesions on the left thigh

\section{Discussion}

Dermatofibromas are ordinary harmless papules or nodules of little more than cosmetic significance and typically present solitary or in a very few numbers on the anterior surface of the lower legs in middle-aged women ${ }^{[1]}$. Instead of being benign tumours, they probably represent a pattern of fibrous reaction to trauma, virus, or insect bite ${ }^{[2]}$. Multiple dermatofibroma is a term when more than 15 dermatofibromas appear and it is a rare condition.

The first clinical variant of multiple form of DF is when "eruptive-mode" lesions are presented throughout the body at which time they can be associated with some illnesses, especially dermatomyositis ${ }^{[3]}$, immunossupressive therapy $^{[4]}$ HIV infection ${ }^{[5]}$ or antiretroviral therapy ${ }^{[6]}$.

Congenital multiple clustered dermatofibroma is a second form of presentation of multiple DF and is differentiated by the pediatric-age onset ${ }^{[7,8]}$.

Multiple clustered dermatofibroma (MCDF) is a third and distinct entity which usually appears during the first or second decade of life. This variant of MCDF which is neither congenital nor eruptive is extraordinarily rare, with only 13 cases reported. The clinical characteristics

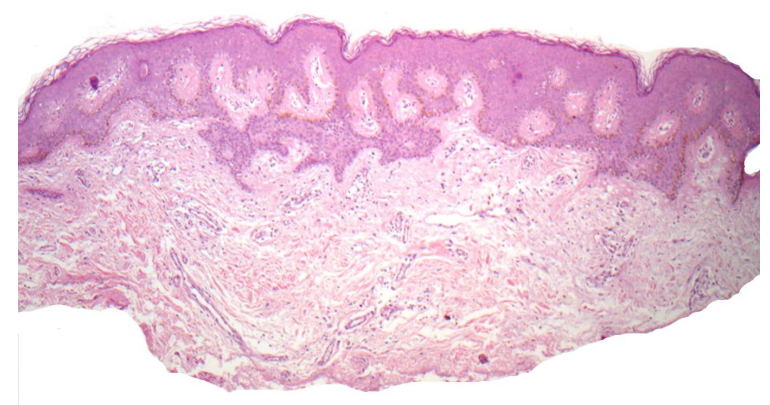

Figure 3. Biopsy of the thigh lesion. Fibrohistiocytic proliferation with epidermal hyperplasia and pigmented rete ridges.

[Hematoxylin and Eosin (H\&E) staining, X50]

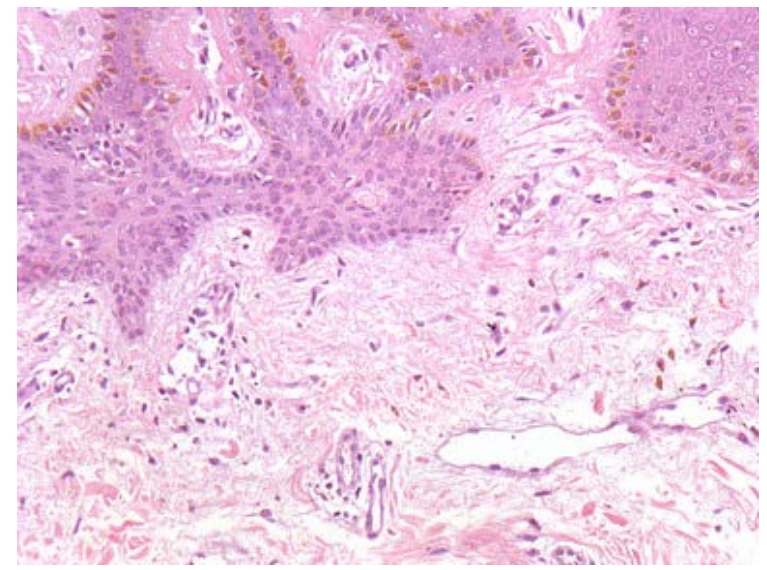

Figure 4. Higher magnification revealing pigmented rete rigdes, epidermal hyperplasia, fibrohistiocytic proliferation, widened vessels and thickened collagen bundles. (H\&E staining, X200)

of this case shows all the features common to all cases of this variant form of DF previously reported, these being, occurrence in healthy individual in the second decade, slowly progressive evolution increasing over many years $^{[9,10]}$ and DF typical lesions. The location on the left buttock is also quite typical, and 2 biopsies on different places were consistent with dermatofibroma ${ }^{[11,12]}$.

In our case the patient was asymptomatic, with pericardial cyst accidentally identified. Pericardial cysts are very rare and represent congenital defect of mesenchymal lacunae to form pericardial sac. While mostly asymptomatic, they may cause dyspnea and cough and may require surgical excision. The association with MCDF may be casual but is reported here for further studies.

The prognosis of MCDF is benign and the appearance is the only concern. Lesions usually tend to stop enlarging over decades and some improvement in the appearance of the lesions may be observed. Surgical modalities may be an option, but secondary scarring is of concern. Patients should be reassured that no further work up is needed. Patient refused further treatment, when reassured that the condition is benign. Our case also adds one more report of MCDF to the known literature also favoring the recognition 
of this variant, hence avoiding unnecessary and stressful investigations.

\section{Conflict of interest}

The authors declare no potential conflict of interest with respect to the research, authorship, and/or publication of this article.

\section{References}

1. Bhabha FK, Magee J, Ng SY, Grills CE, Su J, et al. Multiple clustered dermatofibroma presenting in a segmental distribution. Australas J Dermatol 2016; 57(1): e20-e22. doi: 10.1111/ajd.12257

2. Evans J, Mattacks CA, Clarke T, Pond CM. Dermatofibromas and arthropod bites: Is there any evidence to link the two? Lancet 1989; 334(8653): 36-37. doi: 10.1016/S01406736(89)90267-5.

3. Huang PY, Chu CY, Hsiao CH. Multiple eruptive dermatofibromas in a patient with dermatomyositis taking prednisolone and methotrexate. J Am Acad Dermatol 2007; 57(5): 81-84. doi: 10.1016/j.jaad.2006.05.070

4. Gualandri L, Betti R, Cerri A, Pazzini C, Crosti C. Eruptive dermatofibromas and immunosuppression. Eur J Dermatol 1999; 9(1): 45-47.

5. Ammirati CT, Mann C, Hornstra IK. Multiple eruptive dermatofibromas in three men with HIV infection. Dermatology 1997; 195(4): 344-348.

6. Bachmeyer C, Cordier F, Blum L, Cazier A, Vérola O, et al. Multiple eruptive dermatofibromas after highly active antiretroviral therapy. Br J Dermatol. 2000; 143(6): 13361337. doi: 10.1046/j.1365-2133.2000.03924.x.

7. Pinto-Almeida T, Caetano M, Alves R, Selores M. Congenital multiple clustered dermatofibroma and multiple eruptive dermatofibromas-Unusual presentations of a common entity. An Bras Dermatol 2013; 88(6 Suppl 1): 63-66. doi: 10.1590/ abd1806-4841.20132647.

8. Finch J, Berke A, McCusker M, Chang MW. Congenital multiple clustered dermatofibroma in a 12-year-old girl. Pediatr Dermatol 2014; 31(1): 105-106. doi: 10.1111/j.15251470.2011.01681.x

9. Gershtenson PC, Krunic AL, Chen HM. Multiple clustered dermatofibroma: Case report and review of the literature. J Cutan Pathol 2010; 37(9): e42-e45. doi: 10.1111/j.16000560.2009.01325.x.

10. Berbis P, Benderitter T, Perier C, Frey J, Privat Y. Multiple clustered dermatofibromas. Evolution over 20 years. Dermatologica 1988; 177(3): 185-188. doi: 10.1159/00 0248540 .

11. Shaheen B, Saldanha G, Calonje E, Johnston GA. Multiple clustered dermatofibromas (fibrous histiocytomas): An atypical clinical variant of dermatofibroma. Clin Exp Dermatol 2014; 39(1): 88-90. doi: 10.1111/ced.12200.

12. Soon SL, Howard AK, Washington CV. Multiple, clustered dermatofibroma: A rare clinical variant of dermatofibroma. J Cutan Med Surg 2003; 7(6): 455-457. doi: $10.1177 / 120347540300700604$. 